\title{
Engagement in digital games and web applications using adaptive matching-to-sample tasks in teaching reading
}

\author{
Gilberto Nerino de Souza Junior \\ Lab. of computational intelligence and operational research \\ Federal University of Pará- UFPA, Belém, Brazil \\ gilbertonerinojr@gmail.com \\ Daniel Felipe Lopes \\ Lab. of computational intelligence and operational research \\ Federal University of Pará- UFPA, Belém, Brazil \\ danielfdeus@gmail.com
}

Abner Cardoso da Silva

Lab. of computational intelligence and operational research Federal University of Pará- UFPA, Belém, Brazil abner.cardo@gmail.com

Francielma dos Santos Assunção

Laboratory applied artificial intelligence

Federal University of Pará- UFPA, Belém, Brazil assuncao.francielma@gmail.com

\begin{abstract}
Over the last years, several interactive environments were developed to promote the individualized teaching. These systems can use behavioral procedures to generate tasks and for improving reading skills. This paper proposes two learning interactive environments, a digital game, and a web application, that uses a matching-to-sample procedure to teach reading abilities, where the tasks are adapted to the students by a framework based on evolutionary computing. We applied an experiment to identify the engagement of 22 students assigned from a class of first graders of a Brazilian public school. The students were divided into 4 groups and their data was collected for two days. In questions of engagement, the digital game showed superior acceptance in the use of teaching tasks.
\end{abstract}

Keywords - Engagement, Digital game, Web application, Adaptive tasks, Matching-to-sample, Teaching to read.

\section{INTRODUCTION}

Some researchers say that the process learning to read consists in the symbolic and behavioral aspects that must be established by the children [1], [2]. A child can respond in the same way in front of stimuli that have common characteristics, When this occurs, the stimuli are said to be equivalent to each other [3], [4]. The matching-to-sample procedure (MTS) is a method used for the teaching of the reading relations [5], through of stimuli equivalence paradigm. This paradigm defines symbolic behaviors to confer reciprocity between elements and their properties [6], [7] and is used for the acquisition of basic learning in several knowledge branches [8], [9], [10]. Basically, if an element $\mathrm{A}$ has relation with an element $\mathrm{B}$, and if an element $\mathrm{B}$ has a relation with the element $\mathrm{C}$, the elements $\mathrm{A}, \mathrm{B}$, and $\mathrm{C}$ are equivalents according to [11]. In order for a student to be able to respond " $\mathrm{A}$ is equal to $\mathrm{C}$ ", the relation between each element must be taught.

\author{
Yvan Santos Brito \\ Laboratory applied artificial intelligence \\ Federal University of Pará- UFPA, Belém, Brazil \\ yvanbrito96@gmail.com \\ Dionne Calvacante Monteiro \\ Laboratory applied artificial intelligence \\ Federal University of Pará- UFPA, Belém, Brazil \\ dionne@ufpa.com
}

Ádamo Lima de Santana

Lab. of computational intelligence and operational research Federal University of Pará- UFPA, Belém, Brazil adamo@ufpa.br

In this context, it was observed that the last years produced many interactive education computational environment, and these products can provide improvements in the process of teaching and learning of various knowledge branches. Examples of these environments range from online courses, web based systems, cooperative/competitive social network platforms and educational games that assist in the user satisfaction and engagement growth [12]-[17]. However, in the education behavioral context, adaptive tasks that utilize the MTS procedure were few explored to help children with learning difficulties [18].

Some research that uses the MTS procedure showed important results, like the program called "Aprendendo a Ler e Escrever em Pequenos Passos" (Learning to Read and Write in Small Steps) [19], [20] that aims to help students with reading. Integrated with a computerized manager, this learning program allows the modification of the progress of units of education starting from the pre-established rules [21].

In [15], a digital game was used with a playful plot and the progressive transition of learning tasks based on the student's performance, The learning tasks were presented as a solution of puzzles. The author confirmed that the use of games and web applications aroused the student's interests. This is also reinforced by researchers that suggest that the narrative of a game can be determinant to maintain the player's engagement [22]-[24]. Generally, the learning is sustained for motivational applications and for conventional methods [15], but the students prefer educational methods based on games than other applications without game characteristics [16], [25]. 
Other studies did not use MTS procedure but had considerable results in teaching using motivational and conventional applications. The research in [14] investigated the learning and engagement of Chinese university students in teaching English vocabulary. Two groups were confronted: the first group used an e-Book and the second group used a computational game. In the latter, there were indications of learning in computer games with better knowledge gains than in the first group. [16] developed an educational game with the learning approach situated with the goal to observe learning and engagement in language teaching for sixth-grade Chinese students, confirming that games can engage students in the search for better answers.

In this paper, we investigated the student's engagement in two computer-based environments for teaching Brazilian Portuguese vocabulary in two learning interactive environments that use MTS procedure. These applications were specially developed for this study and were used together with a framework to generate adaptive tasks [26]. The participants were separated into four groups that answered tasks in a web-based application and in a digital game. Based on the results acquired, it was possible to identify the engagement of interactive environments (game and web application) and detect if these environments can be able to receive adaptive MTS tasks for the instruction of children in their early stage of literacy.

\section{THE MATCHING-TO-SAMPLE PROCEDURE}

In matching-to-sample (MTS) procedure, the stimuli formats can be combined according to its relations and represented as types of MTS tasks, as illustrated in TABLE 1 [26]. The common nomenclature: two capital letters together, the first one always referring to the model stimulus and the second to the comparison. The letter " $\mathrm{A}$ " represents the use of sound stimuli, that is, the words dictated; "B" represents the stimuli being arranged in images; and " $\mathrm{C}$ " represents written words.

In the MTS procedure, the student must select between two or more alternatives as a choice when confronted to a model stimulus. After of a? stimulus choice as the answer, reinforcement stimuli are presented as a feedback and indicate that the student had success or failed in the task [7], [11]. This feedback stabilizes the association between the model stimulus and the choices. A sequence of the MTS tasks presented on a teaching session can conduct for a word learning produce the equivalence of stimuli and the association of images, sounds and texts of words [5], [8], [9].

\section{THE LEARNING INTERACTIVE ENVIRONMENTS}

This study proposes the use of two learning interactive environments, specially developed for this research: a web application running in a web browser and an interactive digital game. Both allowed the inclusion of MTS tasks with real time data storage. The interaction between the user and the software occurs through mouse inputs. Both applications cited are available on: http://linc.ufpa.br/amaru-mts/.
TABLE 1. Examples of MTS teaching procedure tasks types. The circular marking indicates the correct choice.

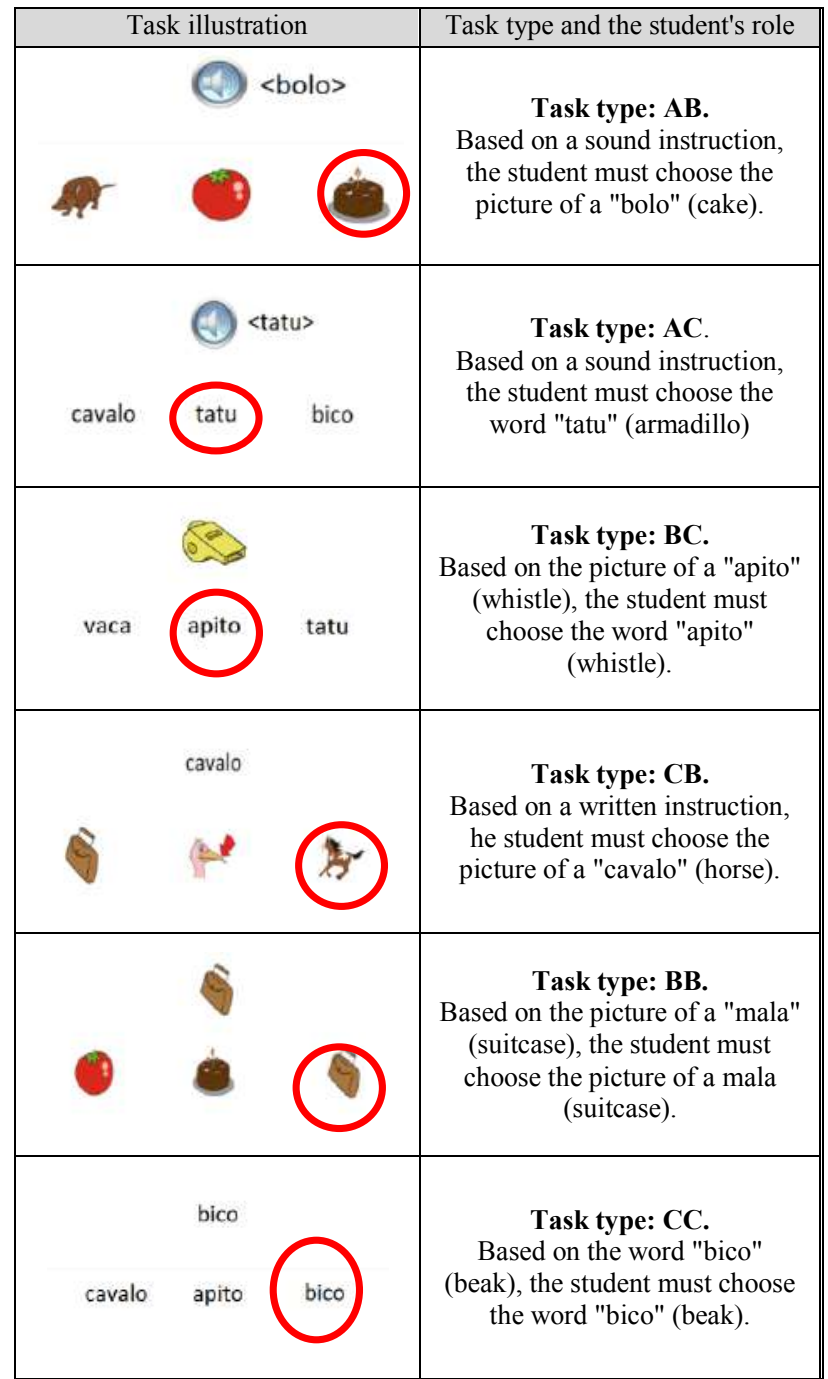

\section{A. The Web Application}

The web application developed for this study is called MTS-Player and this application is similar to classic MTS tests. The MTS-Player application uses visual and sound feedback as an indicator of correctly or incorrectly answered questions. In case the participant desires to stop the training session, they can use an exit button located on the upper left corner of the screen; a progress bar also shows the student's progression in the session. Fig 1 shows two tasks? on MTSPlayer.

\section{B. The Digital Game}

The digital game developed for this study is called "Amaru's adventures" [18]. The game presents the story of an alien named Amaru. In the game's plot, Amaru suffered an accident and falls on Earth with his spaceship. To repair the ship and return to his home planet, Amaru needs to learn to communicate with humans. Amaru has the assistance of a robot friend that helps him learn. After the presentation of the game's plot, a small tutorial is shown to the participant in order to assist in the basic commands of the game.

The tasks are presented as "mini-games" during the game's progression. In these mini-games, the participant must select the correct answer by controlling the main character: jumping and reaching floating cubes (cube minigame) and jumping over platforms (platform mini-game). 
The game allocates the tasks in five game stages and the player can keep track of their progress in a mini-map, according to Fig 2.

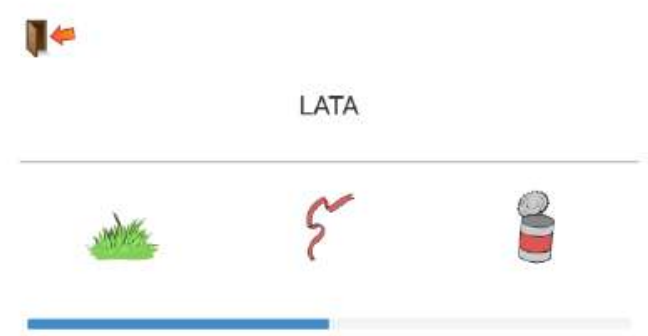

(a)

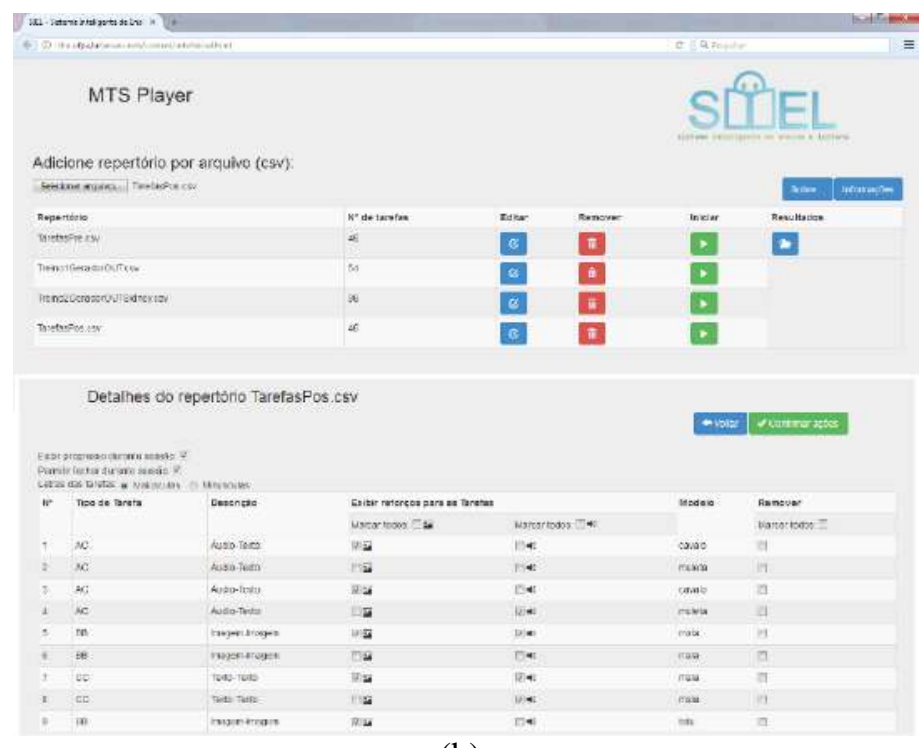

(b)

Fig 1. Web application (MTS-Player), (a) task type CB with LATA (can) as a model of the task, (b) tutor area for management of tasks.

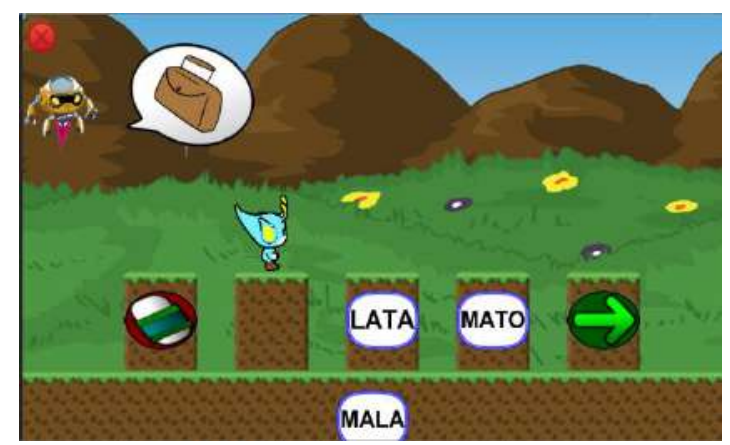

(a)

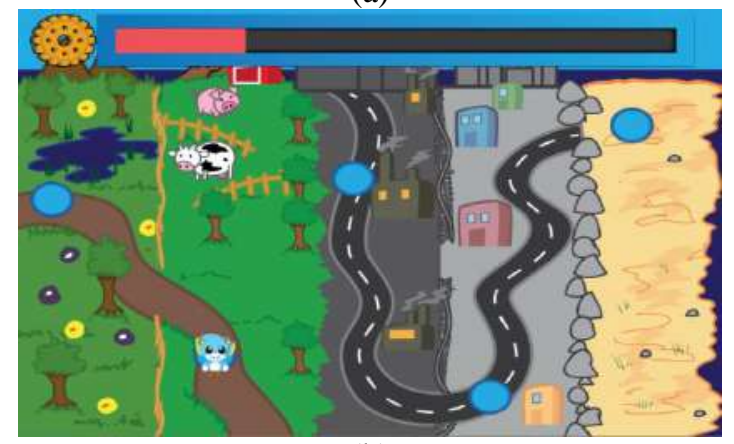

(b)

Fig 2. Pictures from "Amaru's adventures": (a) task type BC on "platform mini-game", (b) The game's mini-map.
In the game, the participant can also collect items during the progression of the stages. The number of items between each mini-game is directly proportional to the number of correct answers. The feedbacks of each task are similar to the web application. It is considered that this is a gamification of the classic MTS tests.

\section{Framework for generation of adaptive teaching tasks}

The educational instructor is essential for teaching [27][29], but the manual construction of sets of tasks can be considered a limitation since the instructor needs to build it for each student taking into account their performance [30]. The framework cited by [26] was used for the generation of individualized tasks, as the adaptive teaching systems based on evolutionary computing. In the framework, the building of new tasks is based on the observation of the student knowledge and the difficulty of the tasks on each iteration.

The process begins with the insertion of initial configuration: a list of words models, tasks types, words choices and levels of difficulty for the activity. The student's performance is calculated based on answered tasks (collected by a pretest), thereafter this results are used to calculate the difficulty of tasks. The iterative and evolutionary process continues calculating the difficulty of tasks and selecting of best tasks. After this process, the set of tasks is included in the learning environments for teaching the students. This process is represented in Fig 3.

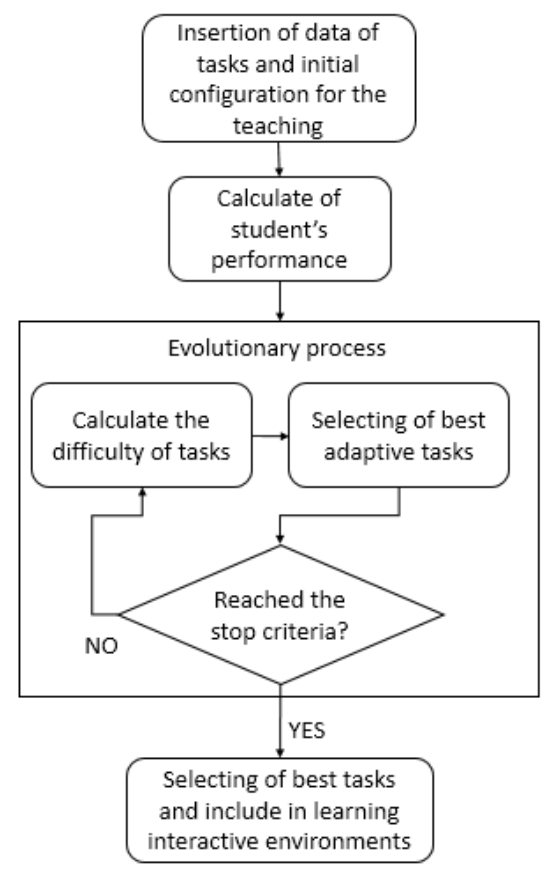

Fig 3. The process to generate of adaptive tasks.

\section{EXPERIMENT TO EVALUATION LEARNING INTERACTIVE ENVIRONMENTS}

In this study, we proposed an experiment to identify the engagement of the students. A semi-structured interview was performed with questions to investigate the difficulty levels of the input commands and the student engagement in using the developed interactive learning environments. With the public being children in initial literacy, the proposed questions were simple, using the liberty of a semi-structured interview [31].

The experiment was conducted in a computer laboratory of the Federal University of Pará, Belém, located in the north of Brazil. Headphones were made available for the 
students to listen to each audio sample produced by the computer. The location was also adequately air-conditioned for the execution of the activities and to provide the learning. Fig 4 shows a session of activity

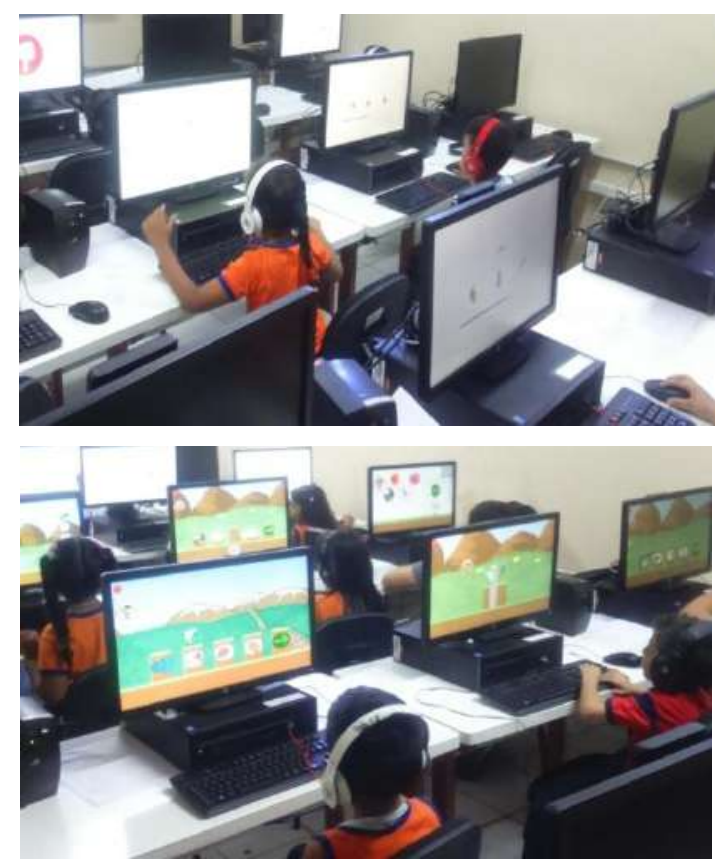

Fig 4. Experiment in the computer lab.

The experiment was performed with 22 invited students from a public school, including 11 males and 11 females, ages between 6 and 7. The student's choice was based on the level of schooling that contemplates the literacy phase, that is, the first grade. A term of consent was signed by the school's pedagogic coordination and the student's legal guardians to authorize the experiment. The participants performed to 2 sessions of 30-50 minutes each. The participants were randomly divided into four groups: "Group A: Web-Game", "Group B: Game-Web", "Group C: Web-Web" and "Group D: Game-Game".

According to Fig 5, in the first moment of the first day, the participants had a small orientation on the use of computational applications. In the second moment of the first day, the participants were presented to the tasks. The sets of "tasks 1" and "tasks 2" were different tasks and were performed on the first and second day respectively. In a third moment, the semi-structured interview was applied individually. This structure was replicated in a similar manner on the second day.

The interviewers observed the expression and speech of the student. The answers of interviews were categorized in three responses for each question: yes (positive answer), no (negative answer) and no response (neutral answer). For example: the child gesturing the head positively and confirming the response was noted as "yes"(positive answer); the speak as "cool", "good", "cute" were noted as "yes"(positive answer) and the speak as "bad", "silly", "ugly" noted as no (negative answer).

The questions answered by groups on the semistructured interview were: Q1, "Did you like the activity?"; Q2, "Would you like to do the activity again?"; Q3, "Did you feel like continuing the activity?"; Q4, "What were the commands you used in the activity? (Yes, if the student can use the commands of keyboard and mouse correctly)"; Q5, "Were you able to do the activity?". Another question, Q6, was only applied to the "Group A: Web-Game" and "Group B: Game-Web" to collect the tools preference: "Which tool do you prefer?".

\section{RESULTS}

From the 22 participants, 4 students did not appear in at least one session of the experiment, for these reasons, their data were discarded. A total of 18 students finishes the activity: 5 of Group A: Web-Game, 6 of Group B: GameWeb, 4 of Group C: Web-Web and 3 of Group D: GameGame.

All student answered that liked the activities with the tools (Q1), with 100\% answered "Yes" to the question "Did you like the activity?" in the two days. For the other questions, the answers were compiled in Fig 6.

The visual inspection shows that most of the students were able to do the activity for the two days. This reveals the web application and the game were noted as interesting by the participants.

For the groups that use the web application (especially for the Group $\mathrm{C}$ ), the graphs show disengagement characteristics. That is because there is a low number of positive responses from the first to the second day in questions about "Would you like to do the activity again?" (Q2) and "Did you feel like continuing the activity?" (Q3). In question "Were you able to do the activity?" (Q5), there was little variation with almost $100 \%$ of positive responses.

In question Q4 - "What were the commands you used in the activity? (Yes, if the student can use the commands of keyboard and mouse correctly)"- we verified that the Group A Web-Game had more low positive answers on the second day than on the first day. The Group D Game-Game had a low-level positive answer on the first day, but on the second day, the students answered correctly the commands used in the game. We highlight that the students in Group D GameGame used the game in the two days of the experiment, so the learning of this group, about the commands, had more stimulus than others groups. Thus, the game application has more commands and complexity than the web application, such as character's movements and diverse options that vary according to the mini game used. Despite the game having more commands and complexity, with the use of this computing environment, the game's commands are better assimilated by the students. 


\begin{tabular}{|c|c|c|c|c|c|c|}
\hline Groups & $\begin{array}{c}\text { First day - first } \\
\text { moment }\end{array}$ & $\begin{array}{c}\text { First day - } \\
\text { second moment }\end{array}$ & $\begin{array}{c}\text { First day - third } \\
\text { moment }\end{array}$ & $\begin{array}{l}\text { Second day - } \\
\text { first moment }\end{array}$ & $\begin{array}{c}\text { Second day - } \\
\text { second moment }\end{array}$ & $\begin{array}{l}\text { Second day - } \\
\text { third moment }\end{array}$ \\
\hline $\begin{array}{c}\text { Group A: Web- } \\
\text { Game }\end{array}$ & \multirow{4}{*}{ Orientation } & $\begin{array}{l}\text { Execution of set } \\
\text { of tasks } 1 \text { with } \\
\text { the application } \\
\text { web }\end{array}$ & \multirow{4}{*}{$\begin{array}{c}\text { Fist time of } \\
\text { execution of } \\
\text { semi-structured } \\
\text { interview }\end{array}$} & \multirow{4}{*}{ Orientation } & $\begin{array}{l}\text { Execution of set } \\
\text { of tasks } 2 \text { with } \\
\text { the game }\end{array}$ & \multirow{4}{*}{$\begin{array}{l}\text { Second time of } \\
\text { execution of } \\
\text { semi-structured } \\
\text { interview }\end{array}$} \\
\hline $\begin{array}{c}\text { Group B: Game- } \\
\text { Web }\end{array}$ & & $\begin{array}{l}\text { Execution of set } \\
\text { of tasks } 1 \text { with } \\
\text { the game }\end{array}$ & & & $\begin{array}{c}\text { Execution of set } \\
\text { of tasks } 2 \text { with } \\
\text { the application } \\
\text { web }\end{array}$ & \\
\hline $\begin{array}{c}\text { Group C: Web- } \\
\text { Web }\end{array}$ & & $\begin{array}{c}\text { Execution of set } \\
\text { of tasks } 1 \text { with } \\
\text { the application } \\
\text { web }\end{array}$ & & & $\begin{array}{c}\text { Execution of set } \\
\text { of tasks } 2 \text { with } \\
\text { the application } \\
\text { web }\end{array}$ & \\
\hline $\begin{array}{c}\text { Group D: Game- } \\
\text { Game }\end{array}$ & & $\begin{array}{l}\text { Execution of set } \\
\text { of tasks1 with } \\
\text { the game }\end{array}$ & & & $\begin{array}{c}\text { Execution of set } \\
\text { of tasks } 2 \text { with } \\
\text { the game }\end{array}$ & \\
\hline
\end{tabular}

Fig 5. The design of the experiment.
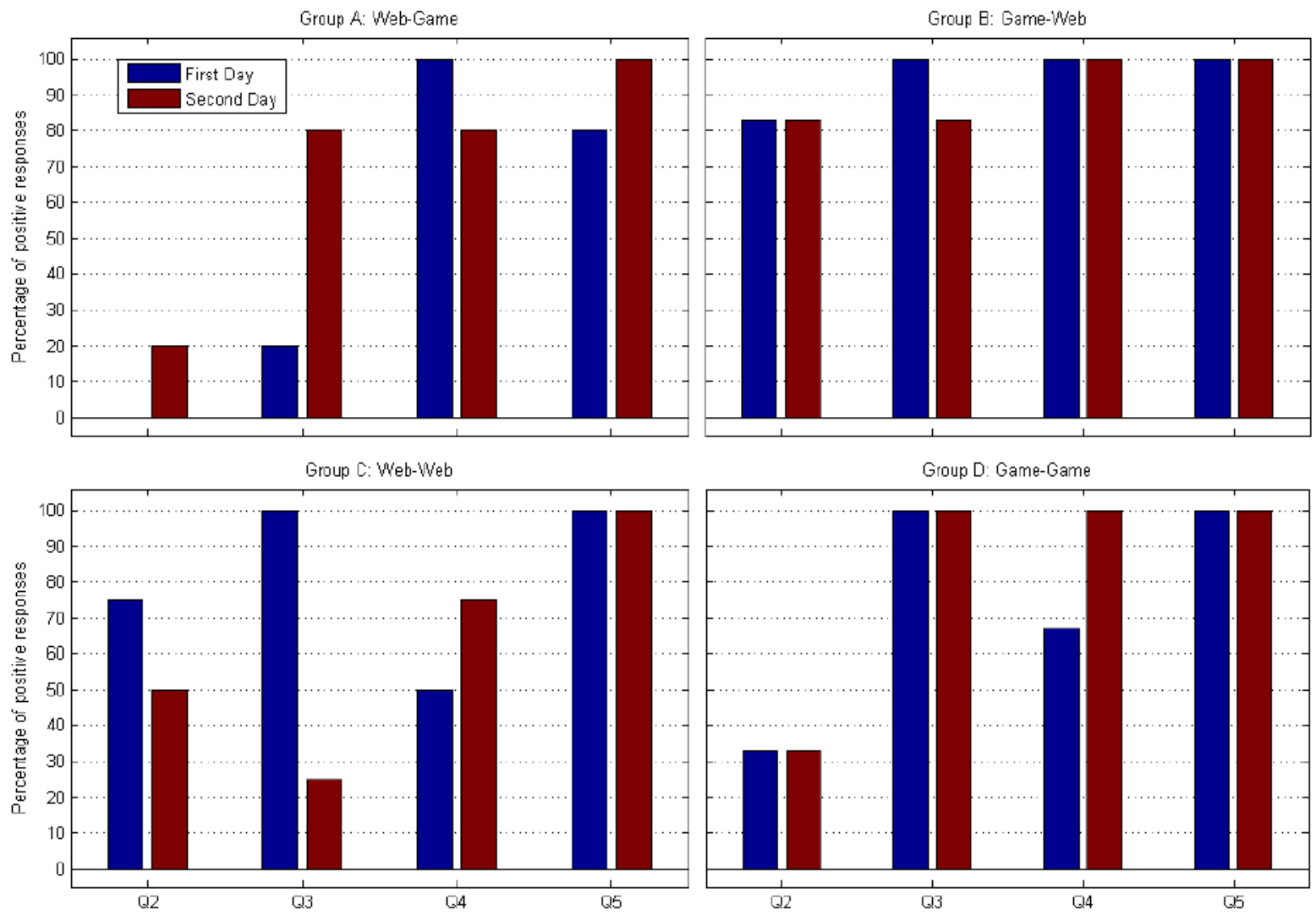

Fig 6. Percentage of positive responses in the two days of the experiment for four questions on legend and for four groups.

In relation to preference between the interactive environments (Q6), the "Group A: Web-Game" has a total of $83 \%$ that prefer the game and $17 \%$ did not answered the question. The "Group B: Game-Web" has a total of 50\% that prefer the game, $17 \%$ do not prefer the web application and $33 \%$ did not answered the question.

This result shows a preference for the digital game, but both tools were accessible to this class. This research also indicates that even without prior training, continuous exposure to sets of tasks is enough for participants to learn how to handle the tools.

\section{CONCLUSION}

This paper presented a study about learning tools as interactive environments assisted by a framework to generate adaptive tasks for students using MTS tasks for teaching reading. The experimental results, regarding the engagement questions, presented an indication that MTS tasks in a game environment are more suitable for children in the initial learning phase. The perception of this characteristic was found due to the use of a web application with only MTS tasks, where no animation and no attractive interactions were exhibited for students. However, to students with difficulties in the operation of the controls and commands of peripherals like keyboard and mouse, it is recommended the use of the web application, due to this application has a simpler interface than the game.

Finally, this study intends to help in the reduction of reading learning deficits in children and to assist educators. Some future works are encouraged as adjusting automatically the parameters educational and new proposals 
of systems for decision-making for instructors in online environments.

\section{ACKNOWLEDGMENT}

We would like to acknowledge the team of the municipal school Edson Luis for the pedagogical assistance, in particular, Mrs. Sandra Nazaré Parente de Oliveira. This research was conducted during a scholarship supported by the cooperation program CAPES/PGPTA at the Federal University of Pará and FAPESPA (Brazilians Agency for Support and Evaluation of Graduate Education).

\section{REFERENCES}

[1] M. M. Mueller, D. J. Olmi, and K. J. Saunders, "Recombinative generalization of within-syllable units in prereading children.," $J$. Appl. Behav. Anal., vol. 33, no. 4, pp. 515-31, 2000.

[2] E. S. Hanna, C. A. Karino, V. T. Araújo, and D. D. G. De Souza, "Leitura recombinativa de pseudopalavras impressas em pseudoalfabeto: similaridade entre palavras e extensão da unidade ensinada," Psicol. USP, vol. 21, no. 400359, pp. 275$311,2010$.

[3] M. Sidman and W. Tailby, "Conditional discrimination vs. matching to sample: an expansion of the testing paradigm.," $J$. Exp. Anal. Behav., vol. 37, no. 1, pp. 5-22, Jan. 1982.

[4] V. B. Haydu, "O que é equivalência de estímulos?," Primeiros passos em análise do comportamento e cognição, 2003. [Online] Available:

https://www.researchgate.net/publication/263178828_O_que_e_e quivalencia_de_estimulos. [Accessed: 28-Feb-2017]

H. A. Mackay, "Stimulus equivalence in rudimentary reading and spelling," Anal. Interv. Dev. Disabil., vol. 5, no. 4, pp. 373-387, 1985.

[6] J. C. de Rose and R. Bortoloti, "A equivalência de estímulos como modelo do significado," Acta Comport., vol. 15, no. SPE, pp. 83-102, 2007.

[7] B. F. Skinner, "Are theories of learning necessary?," Psychol. Rev., vol. 57, no. 4, pp. 193-216, Jul. 1950.

[8] M. R. Dixon, J. Belisle, C. R. Stanley, J. H. Daar, and L. A Williams, "Derived Equivalence Relations of Geometry Skills in Students with Autism: an Application of the PEAK-E

Curriculum," Anal. Verbal Behav., vol. 32, no. 1, pp. 38-45, Jun. 2016.

[9] C. Stanley, "Evaluating the Effectiveness of the PEAK-E in Teaching Receptive Metonymical Tacts Using Stimulus Equivalence Training Procedures," Theses, 2016.

[10] B. D. Walker and R. A. Rehfeldt, "An evaluation of the stimulus equivalence paradigm to teach single-subject design to distance education students via blackboard," J. Appl. Behav. Anal., vol. 45, no. 2, pp. 329-344, 2012.

[11] C. Goyos, "Equivalence Class Formation Via Common Reinforcers Among Preschool Children," Psychol. Rec., vol. 50, no. 4,2012

[12] E. Verdú, M. J. Verdú, L. M. Regueras, J. P. De Castro, and R García, "A genetic fuzzy expert system for automatic question classification in a competitive learning environment," Expert Syst. Appl., vol. 39, no. 8, pp. 7471-7478, Jun. 2012.

[13] L. X. Chen and C. T. Sun, "Self-regulation influence on game play flow state," Comput. Human Behav., vol. 54, pp. 341-350, 2016.

[14] G. G. Smith, M. Li, J. Drobisz, H.-R. Park, D. Kim, and S. D. Smith, "Play games or study? Computer games in eBooks to learn English vocabulary," Comput. Educ., vol. 69, pp. 274-286, 2013
Game-Based Teaching Procedures," Int. J. Game-Based Learn. vol. 3 , no. 1 , pp. 51-62, 2013.

G.-J. Hwang and S.-Y. Wang, "Single loop or double loop learning: English vocabulary learning performance and behavior of students in situated computer games with different guiding strategies," Comput. Educ., vol. 102, pp. 188-201, 2016.

[17] R. Z. Cabada, M. L. Barrón Estrada, and C. A. Reyes García, "EDUCA: A web 2.0 authoring tool for developing adaptive and intelligent tutoring systems using a Kohonen network," Expert Syst. Appl., vol. 38, no. 8, pp. 9522-9529, Aug. 2011.

[18] Pereira A et al., "A AIED Game to help children with learning disabilities in literacy in the Portuguese language," in Simpósio Brasileiro de Jogos e Entretenimento Digital - SBGames, 2012, pp. 134-143.

[19] J. Rose, D. G. de Souza, A. L. Rossito, and T. M. S. de Rose, "Aquisição de leitura após história de fracasso escolar: equivalência de estímulos e generalização," Psicol. Teor. $e$ Pesqui., vol. 5, no. 3, pp. 325-346, 2012.

D. G. de Souza, J. C. de Rose, T. C. Faleiros, R. Bortoloti, E. S. Hanna, and W. J. McIlvane, "Teaching Generative Reading Via Recombination of Minimal Textual Units: A Legacy of Verbal Behavior to Children in Brazil.," Rev. Int. Psicol. Ter. Psicol., vol. 9, no. 1, pp. 19-44, Mar. 2009.

[21] A. F. Orlando, "Uma infra-estrutura computacional para o gerenciamento de programas de ensino individualizados," Universidade Federal de São Carlos, 2009.

[22] K. Kim et al., "Is it a sense of autonomy, control, or attachment? Exploring the effects of in-game customization on game enjoyment," Comput. Human Behav., vol. 48, pp. 695-705, 2015.

[23] M. A. Cezarotto and A. L. Battaiola, "Game Design Recommendations Focusing on Children with Developmental Dyscalculia," Springer International Publishing, 2016, pp. 463473 .

[24] J. McGonigal, Reality Is Broken: Why Games Make Us Better and How They Can Change the World., 1 edition. Penguin Press, 2011.

[25] E. Sarmanho, “ALERPG - Jogo digital como recurso complementar para ensino de crianças com Dificuldade de Aprendizagem em Leitura e Escrita," Universidade Federal do Pará, 2012.

[26] G. Nerino, M. Fontes, D. Monteiro, and Á. Santana, "Um framework para a geração de repertórios de ensino individualizado baseado em dificuldade adaptativa," in XLVIII SBPO Simpósio Brasileiro de Pesquisa Operacional, 2016.

[27] S. Bolkan, "The Importance of Instructor Clarity and Its Effect on Student Learning: Facilitating Elaboration by Reducing Cognitive Load," Commun. Reports, vol. 29, no. 3, pp. 152-162, Sep. 2016.

[28] J. Costley, "The Effects of Instructor Control on Critical Thinking and Social Presence: Variations within Three Online Asynchronous Learning Environments.," J. Educ. Online, vol. 13, no. 1, pp. 109-171, 2016.

[29] J. C. Richardson, E. Besser, A. Koehler, J. Lim, and M. Strait, "Instructors' Perceptions of Instructor Presence in Online Learning Environments," Int. Rev. Res. Open Distrib. Learn., vol. 17, no. 4, Jul. 2016.

[30] C. McMartin-Miller, "How much feedback is enough?: Instructor practices and student attitudes toward error treatment in second language writing," Assess. Writ., vol. 19, pp. 24-35, 2014.

[31] A. Irvine, P. Drew, and R. Sainsbury, “'Am I not answering your questions properly?' Clarification, adequacy and responsiveness in semi-structured telephone and face-to-face interviews," Qual. Res., vol. 13, no. 1, pp. 87-106, Feb. 2013. 